https://helda.helsinki.fi

\title{
What disengages doctoral students in the biological and environmental sciences from their doctoral studies?
}

\section{Virtanen, Viivi}

2017-03

Virtanen , V , Taina , J \& Pyhältö , K 2017 , ' What disengages doctoral students in the biological and environmental sciences from their doctoral studies? ' , Studies in Continuing Education , vol. 39 , no. 1 , pp. 71-86 . https://doi.org/10.1080/0158037X.2016.1250737

http://hdl.handle.net/10138/310684

https://doi.org/10.1080/0158037X.2016.1250737

unspecified

acceptedVersion

Downloaded from Helda, University of Helsinki institutional repository.

This is an electronic reprint of the original article.

This reprint may differ from the original in pagination and typographic detail.

Please cite the original version. 


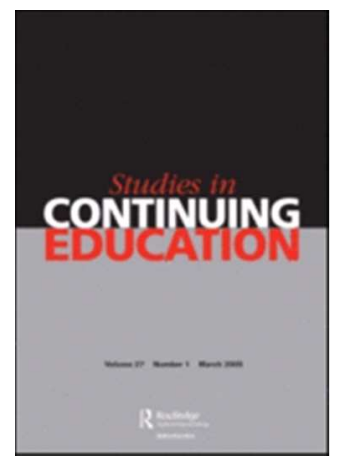

What disengages doctoral students in the bio- and environmental sciences from their doctoral studies?

\begin{tabular}{|r|l|}
\hline Journal: & Studies in Continuing Education \\
\hline Manuscript ID: & Draft \\
\hline Manuscript Type: & Original Article \\
\hline Keywords: & $\begin{array}{l}\text { attribution theory, STEM disciplines, disengagement, doctoral students, } \\
\text { postgraduate education }\end{array}$ \\
\hline \multicolumn{2}{|l}{} \\
\hline
\end{tabular}

SCHOLARONE

Manuscripts 


\section{Introduction}

Disengagement is widely considered a serious problem among doctoral students, a significant number of whom experienced distress, exhaustion and inadequate supervisory support (e.g., Appel and Dahlgren 2003; Kurtz-Costes, Helmke and Ulku-Steiner 2006; Protivnak and Foss 2009), and show astonishingly high attrition rates. Estimates indicate that $30-50 \%$ or more doctoral students (depending on the contexts and countries) abandon their studies (e.g., Golde 2005; McAlpine and Norton 2006).

Previous research on doctoral students has shown a relationship between negative mental states and disengagement (Lovitts and Nelson 2000). Also, a variety of reasons for doctoral students' disengagement reports have been identified, including lack of a sense of belonging to the scholarly community, an external locus of control (Anderson 2011), and a reduced sense of competence to conduct doctoral work (Authors 2013b). Studies have also shown that destructive frictions in student-environment dynamics may reduce student persistence and engagement (e.g., Gilbreath, Kim and Nichols 2011; Golde 2005).

However, the evidence for disciplinary differences in terms of doctoral student disengagement is somewhat contradictory. Some have suggested that doctoral students in STEM disciplines (Science, Technology, Engineering, Mathematics) are more likely than students in the humanities to complete their PhDs. Studies have also shown doctoral students in STEM disciplines to have higher completion rates and faster completion times than their counterparts in the humanities (Seagram, Gould and Pyke 1998; Wright and Cochrane 2000). On the other hand, evidence indicates that doctoral students in the bio- and environmental sciences suffer more from lack of interest in their studies, are less satisfied with their doctoral 
studies and supervision, and are more likely to abandon their studies than students in the humanities (Saari and Moilanen 2011). Evidence also indicates that graduates in the biological sciences may experience greater difficulty finding employment and with further career development after earning their PhD (Yerkes, van de Schoot and Sonnevald 2012). Accordingly, our understanding of what causes doctoral students in the bio- and environmental sciences to disengage from their thesis journey is insufficient; hence, the need to obtain a deeper understanding of the nature and sources of this disengagement.

This study aims to investigate the anatomy of doctoral students' disengagement by exploring the forms of and reasons for it. Analysing doctoral student disengagement enables one to identify the central developmental objectives of doctoral education and to further develop more engaging learning environments for doctoral students and even to prevent dropouts due to disengagement.

\section{Disengagement}

Conducting doctoral research can be reflected in terms of both academic work and studying. Students take their first steps as professional researchers by carrying out doctoral research while at the same time being trained to become researchers (Authors et al. 2013a; Authors 2012c). This is particularly true in Finland, where doctoral studies focus heavily on conducting research, rather than on coursework. The doctoral degree entails a doctoral thesis, seminars, coursework, and a public defence. No extensive separate coursework need be completed before undertaking doctoral research. Coursework (from 40 to 60 ECTS, depending on the discipline) in doctoral studies is usually individually designed to support the thesis project and is based on personal study plans. Because of this duality, this study 
draws on research from both work (e.g., Schaufeli et al. 2002) and student engagement (e.g., Fredricks, Blumenfeld and Paris 2004).

Disengagement refers to low involvement or passivity in the particular task or activity (e.g., Fredricks et al. 2004; Reeve et al. 2004). It often stems from prolonged work-related stress and is characterised by mental strain, anxiety, distress, and feeling overwhelmed by one's work (Lazarus 1966). Prior research on doctoral experiences shows that many doctoral students face such challenges (Hyun et al. 2006). Disengagement entails emotional, cognitive, and behavioural components, such as negative emotions, reduced levels of effort, and adopting cynical attitudes towards one's work in general (e.g., Demerouti et al. 2001; Schaufeli et al. 2002), and is characterised by low energy, reduced involvement, and experiences of inefficacy (e.g., Maslach and Leiter 2008). Stress typically encompasses feelings of strain and exhaustion resulting from experiencing one's work as overly demanding (e.g., Schaufeli et al. 2002). This feeling may further cause a sense of inefficacy, which relates to the experience of incompetence in one's work (e.g., Schaufeli et al. 2002). Losing interest in one's work and feeling that one's work has lost its meaning often follows reduced involvement. Still, the primary form of disengagement may vary in terms of the context and object of activity. Doctoral students in the behavioural sciences, for example, reportedly experience inefficacy more often than exhaustion from their studies (Authors 2013b). At its worst, disengagement may lead to burnout, which consists of all three assumptions: low energy, cynicism, and experiences of inefficacy (e.g., Maslach, Schaufeli and Leiter 2001). Studies suggest that disengagement yields several outcomes, such as lower levels of commitment (Hakanen, Bakker and Williams 2006) and achievement (Carini, Kuh and Klein 2006; Fredricks et al. 2004), as well as turnover intentions (Fredricks et al. 2004; Schaufeli 
and Bakker 2004). Consequently, disengagement may prevent doctoral students from becoming energetically involved in effective and meaningful thesis work.

\section{Attributions and disengagement}

The problems doctoral students face during their studies are not necessarily negative; in fact, solving complex problems is an essential part of creating new knowledge (Hakkarainen et al. 2014). Such challenges may, however, become stressors if the student receives no adequate support. Some evidence indicates that problems in doctoral studies often originate not from the research process itself, but from the dynamics between the doctoral student and the scholarly community (Hoskins and Goldberg 2005; Authors 2011). In particular, doctoral students' sense of lack of belonging to their scholarly communities (e.g., Deem and Brehony 2000; Moss and Kubacki 2007) has reportedly led to disengagement and even attrition from doctoral studies (e.g., Authors 2012b; Golde 2005). Poor atmosphere, isolation, lack of feedback, and destructive friction within the community are all serious causes of disengagement among doctoral students.

However, individual differences have also been found in the ways in which doctoral student adapt and cope (Amini et al. 2008; Baker and Pifer 2011) with the challenges they encounter in their studies. Yet, research on doctoral education in a poor predictor of this variation. One reason for the variation between the disengagement that doctoral students experience may be that they perceive such challenges differently, which is likely to compel them to employ various strategies for coping with the challenges. For example, some evidence indicates that doctoral students relatively seldom take an active stance in their scholarly community by, for 
instance, actively seeking opportunities to participate and contribute, by offering feedback to supervisors or by trying to change practices that they find problematic (O'Meara and Campbell 2011; Authors 2012a). Doctoral students' attribution of the nature of the problems they encounter may contribute to individual differences in the disengagement they experience and to additional ways in which they try to solve their problems.

Causal attribution refers to post hoc interpretations or redefinitions of what caused an event (Weiner 1985, 1986). Attributions are significant in terms of doctoral student disengagement, because they provide means to both explain and understand an event that causes disengagement and to guide future student behaviour. Some have suggested that attributions have both a direct and indirect effect on individual adjustment to such challenges (Amirkhan 1998). Research has shown attributions to directly affect individual psychological adjustment and indirectly affect an individual's use of various coping methods (Folkman et al. 1998). In general, prior research on attributions indicates that positive attribution styles are associated with greater use of problem solving and coping styles that involve cognitive restructuring and less use of coping styles that involve reluctance to handle such challenges (ArmstrongStassen 2004; Park and Adler 2003; Webourne et al. 2007).

In this study, we draw on Weiner's $(1985 ; 1986)$ attribution theory, which comprises three attribution dimensions: locus of causality, stability and controllability. Some evidence suggests that an internal locus of control and self-direction is essential for making the most of doctoral education (Anderson and Anderson 2012). For example, in a previous study, the authors (2012) found that doctoral students who felt they had an opportunity to participate in and contribute to their scholarly community (i.e., had some measure of control over their 
working environment) were less likely to drop-out and to suffer from lack of interest in their studies.

\section{The aim}

This study focuses on how and what causes students in the bio- and environmental sciences to disengage from their doctoral studies, and poses the following research questions:

1. What forms of disengagement arise among doctoral students of bio- and environmental sciences?

2. Which kinds of academic activities entail disengaging experiences?

3. To what do doctoral students attribute their disengaging experiences?

4. Did the attributions of doctoral students who were still finishing their doctoral studies differ from those of students who had already completed their doctoral degree?

The present investigation is a part of larger national study of doctoral education: "From doctoral student to scientific expert" (Authors 2009).

\section{Methods}

\section{Participants}

This study included interview data collected from doctoral students in the biosciences at a major research-intensive university in Finland. We interviewed a total of 40 doctoral students $($ male $=15$, female $=25)$ who had either finished their studies three years before the 
interview ( $n=20$; mode 31 years) or were third-year $\mathrm{PhD}$ students $(n=20$; mode 26 years $)$ and thus had the most recent experience of doctoral studies. The participants represented all majors, namely, Aquatic Sciences $(n=5)$, Biochemistry $(n=3)$, Ecology and Evolutionary Biology ( $n=9)$, Environmental Sciences $(n=10)$, General Microbiology $(n=2)$, Genetics (n =4), Physiology $(n=4)$, and Plant Biology $(n=3)$. All the participants wrote their doctoral dissertation in English as a summary of articles, which comprised four to five internationally refereed journal articles, an introduction, and a summary.

\section{Interviews}

The data were collected in 2009 with a semi-structured theme interview. The interview was designed to investigate students' conceptions of conducting their research, their thesis process, and how they saw themselves in it. The interview included questions about how the participants became doctoral students, their motivation, their experiences (both positive and negative) during their doctoral journey, and their experiences of supervision. The students were also asked background questions about the subject and form of their thesis, the time spent in doctoral studies, the estimated duration of the process, and whether they were working on their thesis full- or part-time. The interviews were digitally audio-recorded and transcribed to text files by a trained research assistant.

\section{Analysis}

We used an abductive strategy to analyse the data. At the beginning of the analysis, we developed a functional coding procedure. The data analysis employed the grounded theory approach, which emphasises the constant comparative method for assuring the accuracy of incident codes within each category and for generating the theoretical properties of each category (Harry, Sturges and Klingner 2005). At first, all text segments in which doctoral 
students referred to disengaging experiences, including dissatisfaction, frustration, anger, and any negative emotions, were coded into the same hermeneutic category. The data were then coded into three exclusive main categories: 1) a sense of stress, including feelings of exhaustion and feelings of anxiety; 2) a sense of cynicism, including feelings that their work had lost its meaning; and 3) experiences of inefficacy, including feeling incompetent in one's work. The main categories reflected the sources of disengagement reported by doctoral students and were classified into six basic categories that constituted the primary context in which the disengaging events occurred: a) formal studies, such as doctoral course work; b) external resources; c) research activities; d) the scholarly community; e) the supervisory relationship; and f) time management. The last step served to show how the participants themselves explained their negative emotions by offering explanatory attributions for the particular disengaging experiences. Accordingly, we analysed each disengaging experience across three bipolar attribution dimensions created for the analysis: a) locus of causality (internal-external), b) stability (unstable-stable), and c) controllability (uncontrollablecontrollable). We used cross-tabulations and $\chi^{2}$-tests (significance level $\mathrm{p} \leq .05$ ) to measure the relationship between the attribution given for the disengaging experience and the student group $(\mathrm{A}=$ post docs, and, $\mathrm{B}=$ doctoral students $)$.

At the end of each phase of analysis, the research group validated the categories resulting from the content analysis (Miles and Huberman 1994). In cases of disagreement, we reached consensus on the final categorisation in discussions between the researchers.

\section{Results}


The doctoral students described a variety of disengaging experiences $(f=240)$ embedded in their doctoral studies and which originated from a variety of sources, including both the research process itself as well as the relationship between the student and the academic environment. The experiences ranged from occasional episodes to prevailing practices in the academic environment and fell into three primary forms of disengaging experiences: stress, cynicism, and experiences of inefficacy (Figure 1).

Figure 1 shows that the most typical form of student disengagement was stress (55\%), characterised by feelings of either strain or anxiety. For example, the doctoral students reported that their work was too demanding and stressful. They also described experiences of exhaustion when they did not know how to proceed in their research process, what to do next, or how to resolve problems with their thesis work. These negative emotions, reflecting stress, often occurred during unsuccessful periods at work:

What can't be clear to outsiders is how much your stress level can rise when you think about the second year of research, the time when you feel that nothing was going right. (Student B7)

Work-related stress was also considered as a source of anxiety (13\%), often due to perceived mismatches between one's own personal aims and practices and those of the academic community. Some students felt that they were under considerable external pressure to succeed in their research. Sometimes the students' distress stemmed from a troublesome colleague or lack of confidence between the supervisor and the student him- or herself: And when I started working on my thesis, well, I came under such discipline and rebuke that there was absolutely no limit to it; the email control was 
something utterly terrible, and I always felt that they don't trust me, that they have no faith in me. (Student B6)

\begin{abstract}
About one third of the students' experiences of disengagement took the form of cynicism (29\%). Characteristic of such cynicism was that students felt their thesis work had lost its meaning or that they had lost interest in their work. Often the cynicism seemed connected to ethical issues related to ways of thinking and working in the academic environment. Some students reported negative feelings because they had put so much effort and invested so much into their work and yet, for some reason, their research failed. Consequently, the students reported that their work had lost its meaning:

Mostly, it is just that you lose faith in your project, that none of this has any value. (Student B4)
\end{abstract}

A minority of disengaging experiences were related to students' sense of inefficacy (17\%). In these episodes, students often described not knowing how to proceed in their research because they do not know how to do their work. Thus, the students described their lack of knowledge or skills needed in the various steps of conducting research, such as designing the laboratory experiments or analysing the data:

It was the first time I somewhat felt that I was really lost and wondered how I would get out of this mess that I was in, and how I could write an article about this. Well, I had no actual research question when I went to take them (the samples). (Student B12)

\title{
The contexts of disengaging experiences
}


The disengaging episodes were embedded in various activities of academic life, ranging from unsuccessful experiments, when irreplaceable laboratory samples went down a drainpipe, to a lack of scholarly discussions in everyday working life. The disengaging experiences reported (Figure 2) often occurred while conducting research (30\%), within the supervisory relationship (18\%), or in the scholarly community (16\%). Disengaging episodes took place less often during formal doctoral studies (9\%) or in relation to external resources $(7 \%)$ such as funding.

The participants described having disengaging experiences, such as failure in laboratory experiments while conducting research, carrying out fieldwork, or calculating statistics. They also described various aspects of scholarly communities, ranging from lack of discussions and meetings with other academics to an excessively competitive academic atmosphere. Problems with the supervisory relationship, such as receiving overly critical feedback, lack of emotional support, and discouragement from the supervisor, were considered the main sources of disengagement. Some students described disengaging experiences embedded in the formal coursework or institutional activities of their doctoral studies. Only a few of the participants regarded financial resources and structures as significant contributors to their disengagement. These students often reported investing lots of energy in worrying and applying for resources. Table 1 shows the contexts of these disengaging experiences in order of frequency within the forms of disengagement identified in this study.

In many cases, the research process itself was a source of doctoral students' negative emotions $(\mathrm{N}=36 \%)$. These experiences, ranging from difficulties in data collection to completion of the thesis for the dissertation, occurred throughout the study process. Students 
often felt they lacked the ability to perform a task properly, especially at the beginning of the doctoral process. They also suffered stress and feelings of inefficacy while preparing their first manuscript, designing their study plan, compiling their research questions, or solving methodological problems in conducting their laboratory work:

Well, there was difficult, difficult stuff - technical problems. When we did something, we went through a very frustrating period of a few months before we got things working ... (Student A2)

Students also reported difficulties related to publishing, which evoked feelings of strain. Research-related problems, such as rejection from the journal editor, induced stress, even if they successfully completed the process later. However, the students also described deep dissatisfaction with common practices within the academic community, which evoked cynicism. Sometimes, these practices involved ethical issues in the publishing process:

With one manuscript in particular, I had the same anonymous reviewer arguing about every version. And sometimes, sometimes I think it eventually led to a completely irrelevant or even inappropriate critique. Yes, it was a bit like that. I got the feeling that the reviewer's opinions were biased... Well, I got a feeling that this reviewer was unqualified to do the review, that he or she had an agenda and our manuscript didn't fit into his or her worldview, and that that was the problem. (Student B15)

Sometimes the prolonged difficulties concerned common research practices. Such episodes seemed to evoke negative emotions because the students had no control over their own work and could therefore not know whether, how, or when they could proceed with their research. 
Some students even reported intentions to abandon their studies due to practical difficulties in conducting their research;

\author{
Well, I had problems gathering data because most of it happened abroad and \\ we, or I, depended on that guy abroad and on how well we could co-operate \\ with him on tasks. Well, at times I felt that none of this makes any sense and \\ that I should just quit; I seriously considered giving all this up. Yes, it was \\ because it was just so difficult to implement it. (Student A18)
}

Further investigation showed that supervision was also a source of disengaging experiences (19\%). Dissatisfaction with supervision often entailed expertise-related deficiencies, such as a supervisor's lack of understanding of the methodology or research topic. On the other hand, personality conflicts also emerged from the descriptions, such as a mismatch in working patterns between the student and the supervisor. Some students considered their supervisors good on a personal level, but still felt dissatisfied because of their lack expertise on the topic. Sometimes the supervision was interrupted because of maternity leave, and once due to the death of the supervisor. That seemed to cause problems for the students, who felt they had to struggle alone with their research:

I got partial support, and it was sort of relevant, but then what happened is that every time I needed more support - well, sort of - I would only get cold water poured on me and very negative feedback. (Student A5)

In addition, students often described the scholarly community as a source for disengaging experiences $(\mathrm{N}=15 \%)$. Many students reported feeling that they did not belong to their scholarly communities. These students often felt alone in conducting their research, and some described having no one with whom to discuss their research topic, either due to lack of 
expertise or lack of interest among nearby academics. Some students pointed out that the strain or stress stemmed from a negative atmosphere in their academic environment. They found the academic culture, with its corrosive criticism and excessive competition, unappealing, or the students own views generally contradicted common thinking and practices in the academic environment:

When he praised this new doctor, in all these years this person had asked only five questions, all of which were pretty good. Well, I remember thinking that I don't want this, that I don't want it to be like this, that learning just can't be like 'you don't ask anything'. Instead, shouldn't you ask at least five questions each day? I never forgot this, and it was typical of the atmosphere where I worked, that asking questions was considered a sign of weakness in learning.

(Student A8)

Problems with time management $(\mathrm{N}=12 \%)$ seemed to result in feelings of exhaustion due to a heavy workload. In some cases, the stress originated from difficulty in finding the balance between work and, for instance, family life. In other cases, the negative feelings stemmed from unsuccessful experiments in the research process. Then, the students had to recall the experiments under an undefined timeframe. The students often felt that any investment in their work was insufficient to stay on schedule:

That it somehow left - felt that it left-you permanently in some kind of delay mode, like, with your own tasks. Because writing the summary and other parts took so much time, I should have had a chance to somehow separate it fully from the other tasks. So I guess it was one thing that still made life tough endless stress - to some extent. (Student A15) 
Negative emotions were seldom related to resources $(\mathrm{N}=11 \%)$, such as problems with funding or the poor outlook for one's career. For instance, students described frustration due to the paucity of career choices. Students also described different funding situations which led to inequality among the doctoral students. They felt that one's competence and salary were completely unrelated to each other. Some of these students mentioned that they considered whether to leave the doctoral study process altogether:

And, and since then, perhaps a few years ago or so, it was clear to me that my future may not be as bright as it first looked; where should I go from here? When we began our studies, nobody told us how we would find work, about future requirements, or how difficult finding employment would be. But in recent years, or perhaps during this last year, I have realised that that is what is next, and I still have no clue what I'm going to do, and that is a pretty horrible thought. (Student B19)

The formal studies included in the doctoral programme were reportedly a source of negative emotions $(\mathrm{N}=7 \%)$. Students frustrated with their studies reported receiving no planning or guidance about what courses to include in their degree. Some of the participants took random courses which they later found to be of no use in their studies, creating a sense of cynicism. Some claimed that they received only useless information and could not apply their knowledge in their research projects at all. They felt frustrated having invested time in something that they found had no value. Some described having no intrinsic interest in participating in the course, and moreover, their participation was sometimes troublesome in practice due to long distances or other difficulties with time management. In general, their descriptions about their formal studies seemed to evoke feelings of cynicism among the doctoral students: 
For four years I was at the graduate school... I don't think I got anything out of it except funding. I think that their co-ordinator sucked big time; it was like a total waste of time. I understand that they meant well, networking and other things, but they didn't implement them the way that you could by meeting after the working day and going for a cup of coffee together or something. Then, closer to the end of the schooling, we had mandatory get-together days where everyone was supposed to be present for networking. I don't like that students should have to plan what the school programme should be. I think it should be the other way round: they develop something, and based on that, we improve it. They had some courses, but I found those that I participated in to be of poor quality. I could have just taken a commercial catalogue and flipped through it, and I would have got the same information. (Student A3)

\section{The reasoning behind disengaging experiences: the attribution dimensions}

Further investigation revealed that the explanatory attributions students gave for their disengaging experiences varied in terms of their locus of causality, stability, and controllability. Figure 3 shows that the students most often perceived the causes of their disengaging experiences as external. Thus, the students blamed others, bad luck, or any element of chance for the disengaging experiences. In turn, an internal attribution, meaning that the students assigned the cause of their negative experiences to their own personal characteristics, such as their ability, moods, or efforts, was rare.

Only external attributions were identified in disengaging experiences originating from the relationship between the student and the scholarly community. Similarly, all the negative 
emotions described in the contexts of resources, formal studies, or supervision were explained as the result of factors other to the student him- or herself. Only one student attributed to that he or she may have influenced his or her own experiences of supervision:

This last year was the first where I realised I should to ask for guidance; that at first I just thought that someone would ask, like, "Hey what is new with your thesis?” Then nobody asked (laughs), which sort of made me lonely. (Student B14)

The attribution dimension of instability typically emerged in the students' negative experiences of the research process itself. Their difficulties, with experiments as well as with the whole writing process, created stressful moments, but only occasionally. On the other hand, problems with funding or with the academic environment, if they occurred, often seemed to persist throughout the doctoral study process. When comparing the attribution dimensions of controllability and uncontrollability, a negative experience was often considered outside one's locus of control in the context of resources, formal studies, supervision, or the relationship between the student and the academic environment. But in the research process, students seemed to have some control even if they found it difficult at that moment to carry on:

The most difficult thing ... that you really have to redo and redo and redo the same thing. Like windmills, they never stop... You really have to fight for it... You submit the paper and it is returned, and you edit it and resubmit it, and so on ... and it takes maybe a year and a half, and then it is returned once again, and you wonder: "What was I doing with this?” You dig up some old papers and you cannot remember anything ... and you start studying/learning all over again ... (Student B13) 
The three attribution dimensions seemed to form a continuum with qualitative differences such that at one end of the continuum were disengaging experiences considered externalstable-uncontrollable, and at the other end of the continuum were the internal-unstablecontrollable experiences. The former experiences seemed to promote severe malcontent and dissatisfaction, engendering feelings of cynicism among students. In such cases, the students often mentioned feeling that they had no control over their own working process and generally felt totally frustrated doing their research:

Each and every project was like banging your head against a wall. Well, closer to graduation, it certainly, like, changed my way of thinking, that it would, like, no longer, well - how do you call it - fancy. Well, it certainly lost any glory in the long run, at least in my case, and perhaps I can see that it has also affected my post doc thinking. That perhaps... I don't know if I burned out or what, but my enthusiasm for the job ended, and perhaps I have a sort of a mental hangover from it. (Student A4)

However, if the challenge did not persist, and the student received sufficient support to manage, the result was less extreme malcontent and fewer long-standing consequences. In such cases, the negative emotions were also attributed to internal factors. These explanations mostly involved negative emotions linked to the research process itself, such as misfortune in doing one's laboratory experiments, difficulties in writing manuscripts, or other challenges of the learning process in doctoral studies. Typical of these descriptions was that negative emotions and disengaging experiences promoted only occasional distress; the students seemed to manage through the difficulties thanks to various coping strategies. For example, students explained that they studied the subject more or found a person to help them or took an international course to learn the methods. Thus, the students themselves could control the working process, which, after improving their initial lack of competence, led to success: 
And then it was, like, really difficult. Statistics is perhaps like this; there are no unique solutions where you do this or you do that. And then you get, like, different viewpoints and no personal advice, like, "Do this." Instead, advice was general, and there was even a person whose advice I didn't understand at all. Perhaps statistics was difficult for me, but really, I couldn't understand at all what one scholar was talking about, and what I did understand, well it sort of fell to the wayside. Perhaps that is just the way it is, that it is impossible to get specific advice about what you can and can't do. It was more like "I will mimic other similar results and how they have got them and then somehow apply them", which I also did. (Student A7)

\section{Are there differences in attribution between post docs and doctoral students}

Further analysis showed mostly no statistically significant differences in attributions for the disengagement that the post docs and doctoral students experienced during their doctoral studies. Both the post docs and doctoral students primarily felt that the problems in their $\mathrm{PhD}$ studies were due to external factors and that they had little control over them.

The only minor difference was on the controllable-uncontrollable axis, in which crosstabulations and $\chi^{2}$-tests showed a relationship between the post docs (Group A) and doctoral students (Group B) $\left(\chi^{2}=5.591, \mathrm{df}=1, \mathrm{p}=0.02\right)$. Even there, participants who graduated found that they had a little less control over their problems than did the doctoral students. Accordingly, it appears that completing a $\mathrm{PhD}$ degree in the bio- and environmental sciences does not positively affect one's opinion about one's studies. It even appears that earning the degree fails to bring the satisfaction typical of new doctors. 


\section{Discussion}

\section{Methodological reflections}

In this study, we collected semi-structured interview data to capture the narratives of episodes that described doctoral students' experiences of disengagement. The aim was thus to identify the kinds of events that promoted student disengagement. However, we were careful not to characterize individual doctoral students in terms of their disengagement experiences, since the focus of this study was to identify the events that contribute to student disengagement rather than to identify students who experience disengagement. The reflective and processoriented research design gave the doctoral students an opportunity to reflect on various aspects of their work and thus the opportunity to study their perceived disengagement. However, further research, especially research with a longitudinal design, is needed to examine the development of disengagement over an extended period of time.

We collected the interview data from 40 doctoral students in the bio- and environmental sciences at a large research-intensive Finnish university. Because of the distinctive features of the discipline (McCune and Hounsell 2005; Lindblom-Ylänne et al. 2006) and the limited sample size, one should exercise caution when generalising the results to other disciplines and to other countries. All the same time, the semi-structured interviews provided a wealth of data to identify and analyse the narratives of episodes that promoted doctoral student disengagement from their thesis work. Accordingly, this study explored episodes of 
disengagement embedded in a variety of academic practices. These findings are therefore transferable to other studies in the field of doctoral student disengagement research.

\section{Findings in the light of existing literature}

The present investigation aimed to advance our understanding of the basic components of disengagement among doctoral students in the bio- and environmental sciences by exploring the episodes that contributed to their disengagement from their thesis work. The study showed that feelings of stress, cynicism and inefficacy were central elements in doctoral students' disengagement from their doctoral work, which may further predict doctoral students' lower studying persistence, as well as higher burnout and even drop-out rates. Accordingly, drawing on recent literature on work and studying engagement (Fredricks et al. 2004; Schaufeli and Bakker 2004) provided functional tools for exploring doctoral student disengagement. The findings also support previous research on doctoral experiences (Authors 2013b), suggesting that doctoral student disengagement is not a single entity and can thus appear in different forms.

Students emphasised stress and cynicism in particular as disengaging experiences, but less often reported episodes causing inefficacy. In particular, students often reported episodes that cause stress, including a sense of strain, anxiety and exhaustion due to lack of progress in their research, problems in their supervisory relationships, and poor time management. Our findings partly contradict the findings of previous studies which suggest that the primary form of doctoral student disengagement is inefficacy (Authors $2012 \mathrm{a}, \mathrm{b}$ ). Contradictory 
evidence of the primary form of doctoral student disengagement may partly stem from the different knowledge practices adopted by research communities in different domains.

This study showed that doctoral studies provided multiple contexts for disengagement. Disengaging experiences varied between the different activities that were part of the doctoral studies. Doctoral students in the bio- and environmental sciences, for example, perceived isolation, indifference, and lack of support and constructive feedback to be sources of cynicism. This is in line with the conclusions of prior studies which suggest that supervision (Brailsford 2010; Scaffidi and Bergmna 2011) and a sense of belonging to the scholarly community (Lovitts 2001; Amini et al. 2008; Spaulding and Rockinson-Szapkiw 2012) are central determinants of the doctoral experience. In our study, stress and inefficacy were more often related to failure or lack of progress in research. Our results indicate that both the context and content of disengaging experiences can vary.

Further investigation showed that doctoral students typically attributed disengaging events to external factors. External attributions were often related to perceiving the source of disengagement as uncontrollable and somewhat stable. The students, for instance, attributed their negative experiences to lack of support or feedback from their supervisors or other members of the scholarly community and felt that they had little or no control over the course of events, which they considered unavoidable and permanent. External-uncontrollable-stable attributions were typical of the disengaging experiences embedded in supervision and the activities of the scholarly community. This may explain why doctoral students have reportedly failed to perceive themselves as active relational agents in their own communities (Authors 2012a). In the literature on negative outcomes, external-uncontrollable-stable attributions are often related to less efficient psychological adjustment, including 
experiencing more distress and the use of avoidance coping (see, e.g., the meta-analysis by Roesch and Weiner 2001). Accordingly, the use of external-uncontrollable-stable attributions in negative experiences embedded in the scholarly community and supervisory relationship may lead to less active coping, and thus more disengagement and even dropping out. For example, evidence indicates that doctoral students in the behavioural sciences, humanities and medicine who perceive themselves as passive in the scholarly community were more likely to abandon their doctoral studies (Authors 2012a).

Students seldom used internal attributions. However, characteristic of the use of internal attributions was their combination with perceptions of problems as both controllable and unstable. Such attributions were related primarily to conducting doctoral research. Prior research on causal attributions in negative events suggests that internal-controllable-unstable attributes are related to not only adaptive coping with stressors, but also to a decrease in selfesteem and more frequent feelings of guilt from not doing enough to solve problems (Greenglass and Fiksenbaum 2009; Schwarzer 1993). An internal locus of control and selfdirection has also proved essential in making the most of doctoral education (Anderson and Anderson 2012). These findings suggest that perceiving a negative event as controllable, internal, and unstable facilitates active, motivated coping, which in turn leads to better adjustment, more effective problem solving, and reduced disengagement despite any possible short-term negative effects.

Studies have shown that successful students generally take more responsibility for their failures and feel that they can manage their problems (Authors 2012a). We therefore assumed that post docs who had already successfully completed their doctoral studies would employ more internal and controllable attributions. However, we found no such differences when 
comparing post-doctoral student attributions of disengaging experiences to doctoral student attributions during their doctoral journey.

\section{Educational implications}

Our results showed that the forms of disengagement ranged from stress to a sense of inefficacy. In terms of developing more engaging learning environments for doctoral students in the bio- and environmental sciences, these results suggest that the cures for disengagement must also be individually tailored depending on whether the student is experiencing stress caused by poor time management, cynicism caused by a lack of experienced supervisory support or inadequacy resulting from a lack of methodological know-how. These cures presume that the form of disengagement is known. For instance, taking time off may reduce stress, but reducing cynicism is likely to require changes in supervisory practices.

The results also showed that disengaging experiences depend on context. Accordingly, a student may simultaneously experience both inefficacy, due to a lack of needed know-how, and stress resulting from a heavy workload. This implies that the source of disengagement may vary not only between individuals, but also between the academic activities at hand. Thus, while promoting an engaging doctoral experience, awareness of what typically triggers disengagement in one's doctoral journey is central.

Our study showed that students often favoured external and uncontrollable attributions of negative experiences, whereas the existing literature indicates that the most influential attributions of negative experiences are controllable and internal. And because attributions 
are always learned, more attention should focus on processing and revising doctoral student attributions of negative experiences (i.e., facilitating one's learning of controllable and unstable attributions) if we seek to reduce student disengagement. This may help students to avoid the disengaging experiences that can cause delays and even drive students to abandon their doctoral studies.

\section{References}

Amini, M., M. R. Dehghani, J. Kojuri, A. Mahbudi, L. Bazrafkan, M. Saber, M., and G. D. S Arekain. 2008. A qualitative study of factors associated with medical students' academic success. Journal of Social Science 4: 247-351.

Amirkhan, J. H. 1998. Attributions as predictors of coping and distress. Journal of Personality and Social Psychology Bulletin 24: 1006-18.

Anderson, B. 2011. Predictive relationships among learner characteristics, academic involvement, and doctoral education outcomes. Dissertation Prepared for the Degree of Doctor of Philosophy. Department of Counseling and Higher Education: University of North Texas, USA.

Anderson, S., and B. Anderson. 2012. Preparation and socialization of the education professoriate: Narratives of doctoral student-instructors. International Journal of Teaching and Learning in Higher Education 24 no.2: 239-51.

Appel, M., and L. Dahlgren. 2003. Swedish doctoral students' experiences on their journey towards a PhD: Obstacles and opportunities inside and outside the academic building. Scandinavian Journal of Educational Research 47 no. 11: 89-110. 
Armstrong-Stassen, M. 2004. Managers' perceptions of their work group and their own performance and well-being following a job transfer. Public Personnel Management 33 no. 1: 47-60.

Austin, A. E. 2002. Preparing the Next Generation of Faculty. Journal of Higher Education 73: $94-122$.

Baker, V. L., and M. J. Pifer. 2011. The role of relationships in the transition from doctoral student to independent scholar. Studies in Continuing Education 33 no. 1: 5-17.

Brailsford, I. 2010. Motives and aspirations for doctoral study: Career, personal, and interpersonal factors in the decision to embark on a history Ph.D. International Journal of Doctoral Studies 5: 15-27.

Carini, R. M., G. Kuh, and S. P. Klein. 2006. Student engagement and student learning: Testing the linkages. Research in Higher Education 47 no. 1: 1-32.

Deem, R., and K. J. Brehony. 2000. Doctoral students access to research cultures-Are some unequal than others? Studies in Higher Education 25 no. 2: 149-65.

Demerouti, E., A. B. Bakker, F. Nachreiner, and W. B. Schaufeli. 2001. The Job DemandsResources Model of burnout. Journal of Applied Psychology 86 no. 3: 499-512.

Folkman, S., R. S. Lazarus, R. J. Gruen, and A. DeLongis. 1986. Appraisal, coping, health status, and psychological symptoms. Journal of Personality and Social Psychology 50: 57180.

Fredricks, J. A., P. C. Blumenfeld, and A. H. Paris. 2004. School engagement: Potential of the concept, state of the evidence. Review of Educational Research 74 no. 1: 59-109.

Gilbreath, B., T.-Y. Kim, and B. Nichols. 2011. Person-environment fit and its effects on 
university students: A response surface methodology study. Research in Higher Education 52 no. 1: 47-62.

Golde, C. M. 2005. The role of department and discipline in doctoral student attrition: Lessons from four departments. Journal of Higher Education 76 no. 6: 669-700.

Greenglass, E. R., and L. Fiksenbaum. 2009. Proactive Coping, Positive Affect, and WellBeing. Testing for Mediation Using Path Analysis. European Psychologist 14 no. 1: 29_ 39.

Hakanen, J. J., A. B. Bakker, and W. B. Williams. 2006. Burnout and work engagement among teachers. Journal of School Psychology 43: 495-513.

Hakkarainen, K., S. Wires, J. Stubb, S. Paavola, P. Pohjola, K. Lonka, and K. Pyhältö. 2013. On personal and collective dimensions of agency in doctoral training: Medicine and natural science programs. Studies in Continuing Education 36 no. 1: 83-100.

Harry, B., K. M. Sturges, and J. K. Klingner. 2005. Mapping the process: An exemplar of process and challenge in grounded theory analysis. Educational Researcher 34: 3-13.

Hyun, J. K., B. C. Quinn, T. Madon, and S. Lustig, S. 2006. Graduate student mental health: Needs assessment and utilization of counseling services. Journal of College Student Development 47 no. 3: 247-66.

Kurtz-Costes, B., A. L. Helmke, and B. Ulku-Steiner. 2006. Gender and doctoral studies: The perceptions of PhD students in an American university. Gender and Education 18 no. 2: $137-55$.

Lazarus, R.S. 1966. Psychological Stress and the Coping Process. New York: McGraw-Hill. Lindblom-Ylänne, S., K. Trigwell, A. Nevgi, and P. Ashwin. 2006. How approaches to 
teaching are affected by discipline and teaching context. Studies in Higher Education 31: 285-98.

Lovitts, B. E., and G. Nelson. 2000. The hidden crisis in graduate education: Attrition from Ph.D. programs. Academe 86 no.6: 44-50.

McAlpine, L., and J. Norton. 2006. Reframing our approach to doctoral programs: An integrative framework for action and research. Higher Education Research and Development 25 no. 1: 3-17.

Moss, G., and K. Kubacki. 2007. Researchers in Higher education: a neglected focus of study. Journal of Further and Higher Education 31 no. 3: 297-310.

McCune, V., and D. Hounsell. 2005. The development of students' way of thinking and practicing in three final-year biology courses. Higher Education 49: 255-89.

Miles, M.B, and A. M. Huberman, A. M. 1994. Qualitative data analysis: An expanded sourcebook. Thousand Oaks, CA: Sage.

Maslach, C., and M. P. Leiter. 2008. Early predictors of job burnout and engagement. Journal of Applied Psychology 93 no. 3: 498-512.

Maslach, C., W. B. Schaufeli, and M. P. Leiter. 2001. Job burnout. Annual Review of Psychology 52 no. 1: 397-422.

O’Meara, K., and C. M. Campbell. 2011. Faculty sense of in Decisions abpit work and family. Review of Higher Education 34 no.3: 447-76.

Park, C. L., and N. E. Adler. 2003. Coping Style as a Predictor of Health and Well-Being Across the First Year of Medical School. Health Psychology 22 no. 6: 627-31.

Protivnak, J. J., and L. L. Foss. 2009. An exploration of themes that influence the counselor 
education doctoral student experience. Counselor Education and Supervision 48 no.4:

$239-56$.

Authors 2012a.

Authors 2012b.

Authors 2009.

Reeve, J., H. Jang, D. Carrell, S. Jeon, and J. Barch. 2004. Enhancing students' engagement by increasing teachers' autonomy support. Motivation and Emotion 28 no. 2: 147-69.

Roesch, S. C., and B. Weiner. 2001. A meta-analytic review of coping with illness: do causal attributions matter? Journal of Psychosomatic Research 50 no. 4: 205-19.

Saari, S., and M. Moilanen. 2011. International Evaluation of Research and Doctoral Training at the University of Helsinki 2005-2010 : RC-Specific Evaluation of BIOSYSTBiological Systematics and Taxonomy. University of Helsinki: Administrative Publications 80/19, Evaluations. pp.1-100.

Scaffidi, A. K., and J. E. Bergman. 2011. A positive postdoctoral experience is related to quality supervision and career mentoring, collaboration, networking and a nurturing research environment. Higher Education 62 no.6: 685-98.

Schaufeli, W. B., and Bakker, A. B. (2004). Job demands, job resources, and their relationship with burnout and engagement: A multisample study. Journal of Organizational Behavior, 25(3),293-315.

Schaufeli, W. B., M. Salanova, V. González-Romá, and A. B. Bakker. 2002. The measurement of engagement and burnout: A two sample confirmatory factor analytic approach. Journal of Happiness Studies 3: 71-92. 
Schwarzer, R. 1993. Measurement of perceived self-efficacy. Psychometric scales for crosscultural research. Berlin, Germany: Freie Universitat Berlin.

Seagram, B. C., J. Gould, and S. W. Pyke. 1998. An Investigation of Gender and Other Variables on Time to Completion of Doctoral Degrees. Research in Higher Education 39 no. 3: 319-35.

Spaulding, L. S., and A. J. Rockinson-Szapkiw. 2012. Hearing their voices: Factors doctoral candidates attribute to their persistence. International Journal of Doctoral Studies 7: 199219.

Authors 2011.

Authors 2013a.

Authors 2013b.

Authors 2012c.

Welbourne, J.L., D. Eggerth, T. A. Hartley, M. E. Andrew, and F. Sanchez. 2007. Coping strategies in the workplace: Relationships with attributional style and job satisfaction. Journal of Vocational Behavior 70 no. 2: 312-25.

Weiner, B. 1985. An Attributional Theory of Achievement Motivation and Emotion. Psychological Review 92 no. 4: 548-573.

Weiner B. 1986. An attributional theory of motivation and emotion. New York, NY: Springer.

Wright, T., and R. Cochrane. 2000. Factors influencing successful submission of PhD Theses. Studies in Higher Education 25: 181-95. 
Yerkes, M.,R. van de Schoot, and H. Sonneveld. 2012. Who are the Job Seekers? Explaining Unemployment among Doctoral Recipients. International Journal of Doctoral Studies 7: 153-16. 
Figure 1. Percentages of the forms of doctoral students' disengaging experiences ( $f=240$ ).

Figure 2. Percentages of disengaging experiences $(f=240)$ taking place during various activities of academic life.

Figure 3. Attribution dimensions of students' disengaging experiments ( $f=240)$.

Figure 4. The attribution dimensions of Groups A and B. 


\begin{tabular}{|c|c|c|c|c|}
\hline \multirow[b]{2}{*}{$\begin{array}{c}\text { Contexts of } \\
\text { disengagement }\end{array}$} & \multicolumn{4}{|c|}{ Forms of disengagement } \\
\hline & $\begin{array}{l}\text { Stress } \\
\mathrm{f} \\
(\%)\end{array}$ & $\begin{array}{l}\text { Cynicism } \\
\mathrm{f} \\
(\%)\end{array}$ & $\begin{array}{l}\text { Inefficacy } \\
\text { f } \\
(\%)\end{array}$ & $\begin{array}{l}\text { Total } \\
f \\
(\%)\end{array}$ \\
\hline Research process & $\begin{array}{l}45 \\
(19 \%)\end{array}$ & $\begin{array}{l}13 \\
(5 \%)\end{array}$ & $\begin{array}{l}30 \\
(12 \%)\end{array}$ & $\begin{array}{l}88 \\
(36 \%)\end{array}$ \\
\hline Supervision & $\begin{array}{l}25 \\
(11 \%)\end{array}$ & $\begin{array}{l}15 \\
(6 \%)\end{array}$ & $\begin{array}{l}4 \\
(2 \%)\end{array}$ & $\begin{array}{l}44 \\
(19 \%)\end{array}$ \\
\hline $\begin{array}{l}\text { Scholarly } \\
\text { community }\end{array}$ & $\begin{array}{l}17 \\
(7 \%)\end{array}$ & $\begin{array}{l}18 \\
(7 \%)\end{array}$ & $\begin{array}{l}3 \\
(1 \%)\end{array}$ & $\begin{array}{l}38 \\
(15 \%)\end{array}$ \\
\hline Time management & $\begin{array}{l}26 \\
(11 \%)\end{array}$ & (2) & 3 & $\begin{array}{l}29 \\
(12 \%)\end{array}$ \\
\hline Resources & $\begin{array}{l}15 \\
(7 \%)\end{array}$ & $\begin{array}{l}8 \\
(4 \%)\end{array}$ & - & 23 \\
\hline Formal studies & $\begin{array}{l}3 \\
(1 \%)\end{array}$ & $\begin{array}{l}15 \\
(6 \%)\end{array}$ & - & $\begin{array}{l}18 \\
(7 \%)\end{array}$ \\
\hline Total & $\begin{array}{l}131 \\
(54 \%)\end{array}$ & $\begin{array}{l}69 \\
(29 \%)\end{array}$ & $\begin{array}{l}40 \\
(17 \%)\end{array}$ & $\begin{array}{l}240 \\
(100 \%)\end{array}$ \\
\hline
\end{tabular}




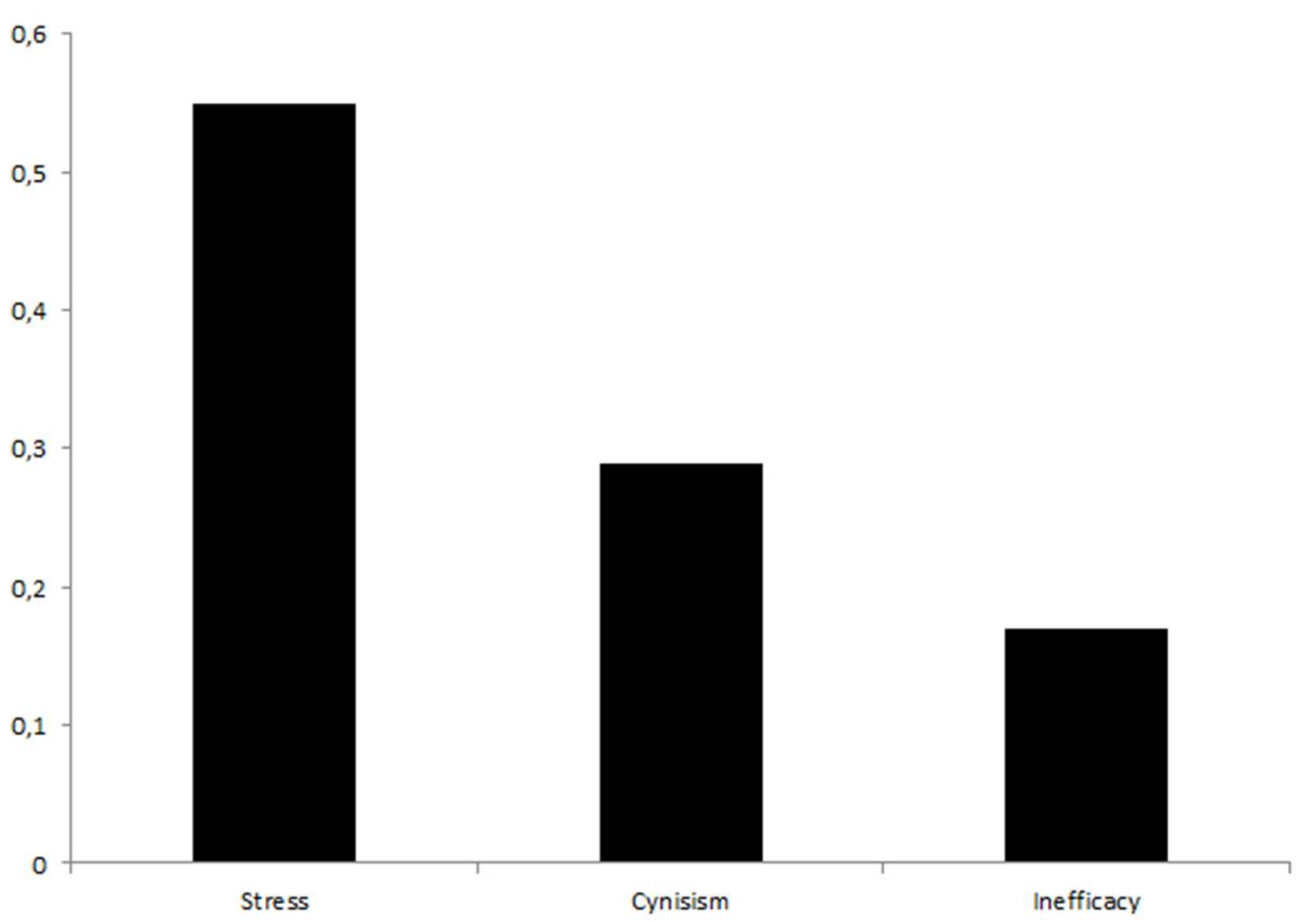

Figure 1. Percentages of the forms of doctoral students' disengaging experiences $(f=240)$. $132 \times 93 \mathrm{~mm}(120 \times 120$ DPI $)$ 


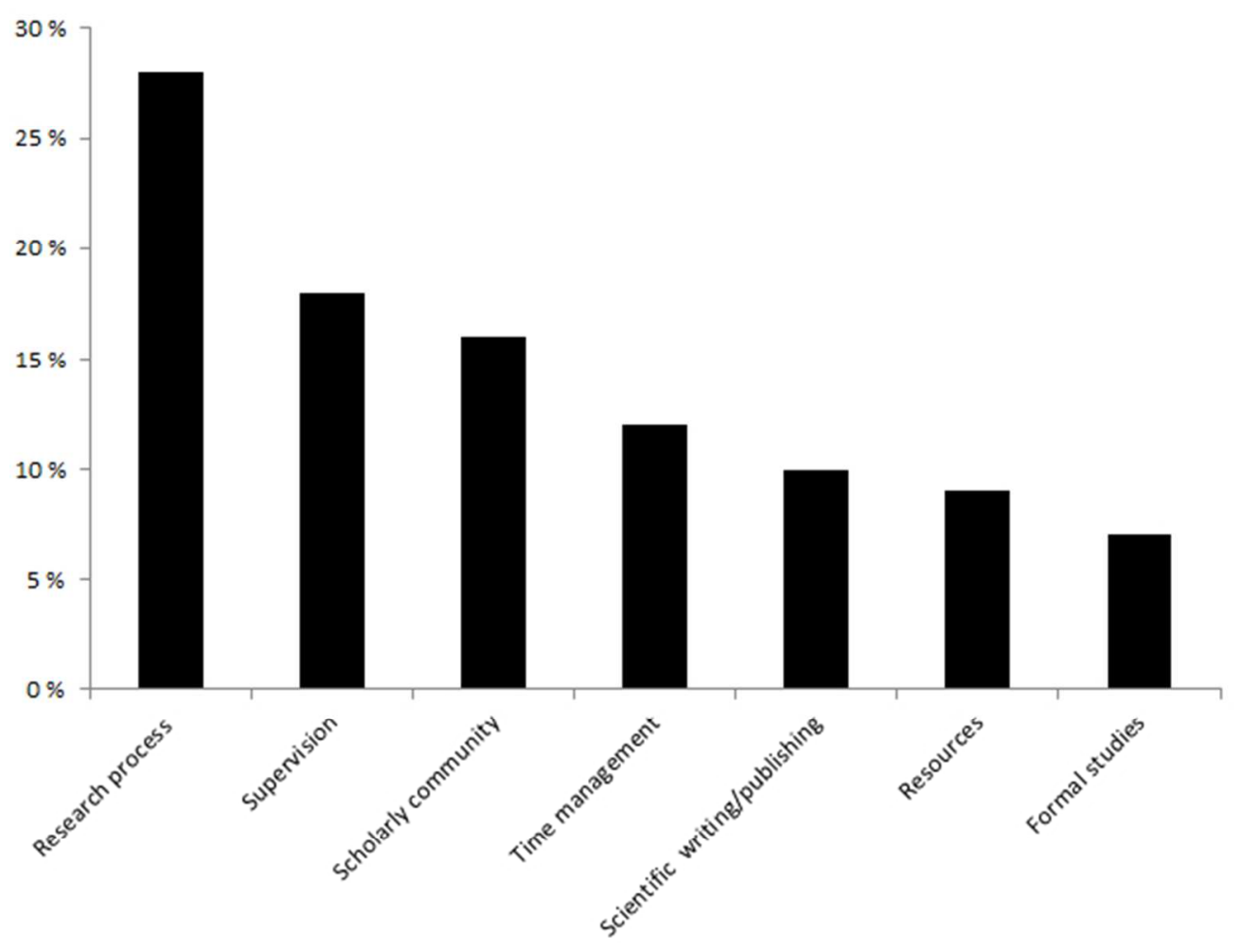

Figure 2. Percentages of disengaging experiences $(f=240)$ taking place during various activities of academic life. $132 \times 102 \mathrm{~mm}(120 \times 120$ DPI $)$ 


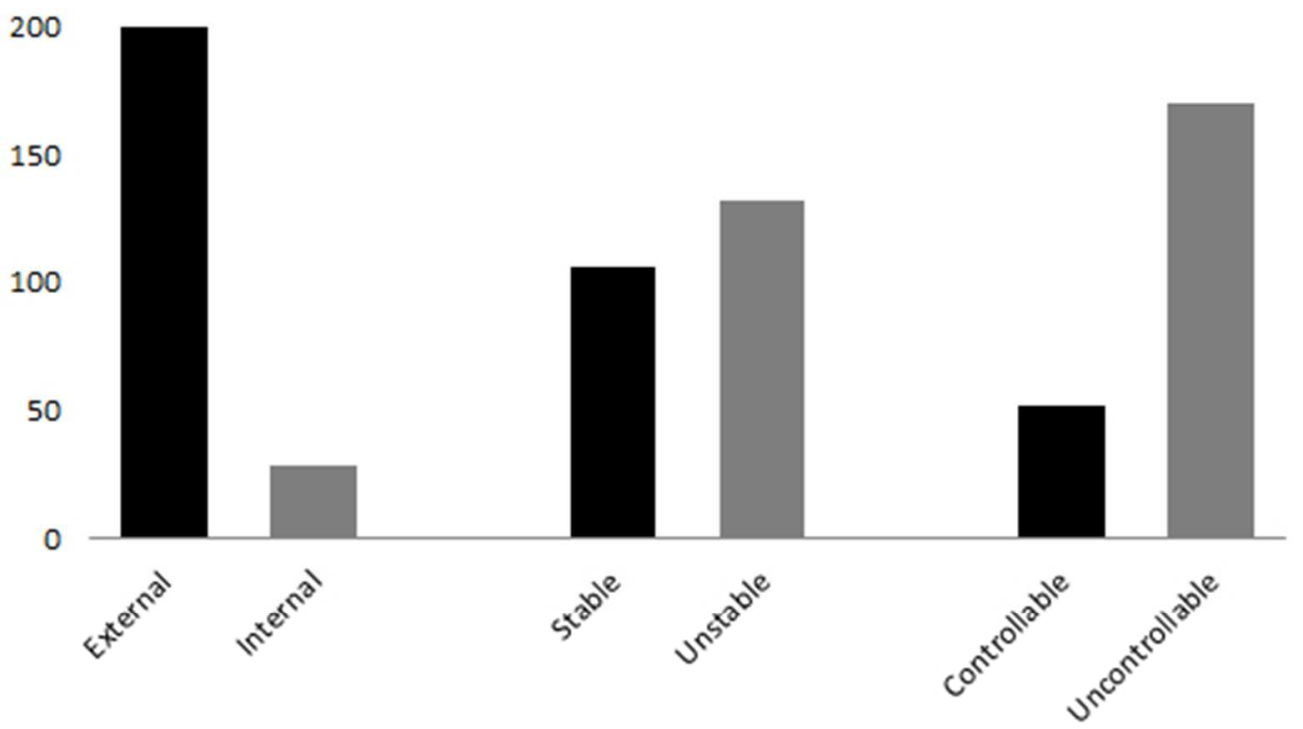

Figure 3. Attribution dimensions of students' disengaging experiments $(f=240)$. $110 \times 66 \mathrm{~mm}(120 \times 120 \mathrm{DPI})$ 


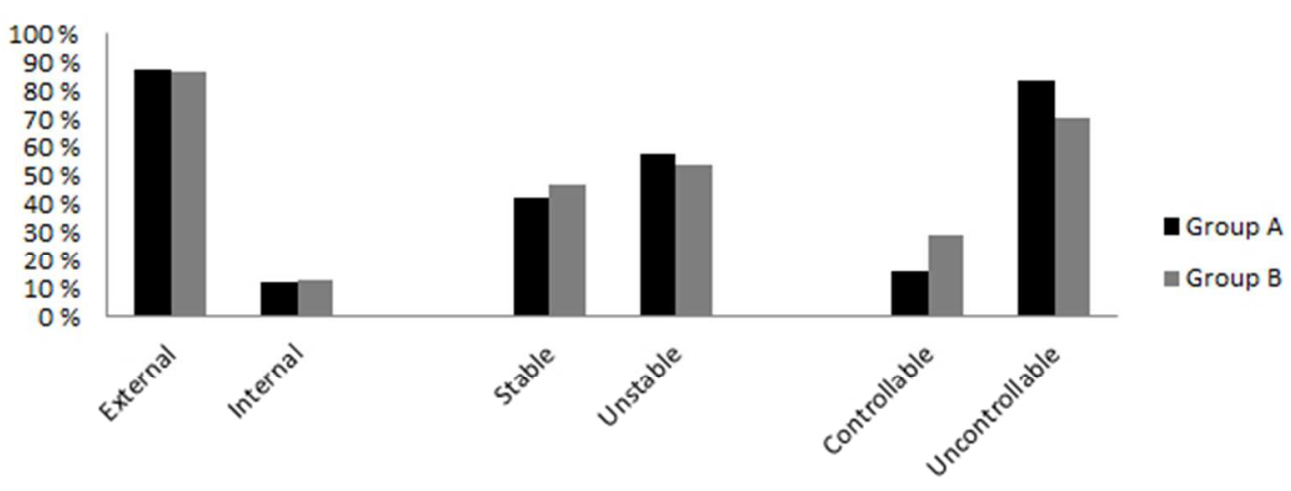

Figure 4. The attribution dimensions of Groups A and B. $126 \times 47 \mathrm{~mm}(120 \times 120 \mathrm{DPI})$ 